\title{
Carboxyhaemoglobin levels in workers in Leicestershire garages
}

\author{
G. R. KELMAN ${ }^{1}$ AND T. J. DAVIES ${ }^{2}$
}

From the ${ }^{1}$ Employment Medical Advisory Service, 48 Princess Road East, Leicester, and the ${ }^{2}$ Department of Chemical Pathology, Leicester Royal Infirmary, Leicester

ABSTRACT Blood carboxyhaemoglobin $\left(\mathrm{Hb}_{\mathrm{CO}} \%\right.$ ) levels were measured in 61 workers in 35 garages in Leicester and Leicestershire. Of 26 workers in large garages in winter, $44 \%$ of the nonsmokers and $20 \%$ of the smokers had increased $\mathrm{CO}$ absorption, the highest $\mathrm{Hb}_{\mathrm{CO}} \%$ being 26.0 in a non-smoker. Of 35 workers in 24 smaller, randomly chosen garages visited throughout the year (two per month) the corresponding figures were $43 \%$ and $14 \%$, the highest $\mathrm{Hb}_{\mathrm{co}} \%$ being $21 \cdot 0$. The possible relevance of these findings to coronary heart disease in garage workers is discussed.

Petrol engine exhaust gases may contain up to $13 \%$ carbon monoxide (CO), depending on the engine's adjustment (Lawther, 1975). Garage workers are therefore at risk of absorbing significant amounts of CO during their daily work; the present investigation was planned to see if this theoretical risk is borne out in practice.

Our interest in this problem started when a man became semiconscious while painting the car showroom of a local garage, and was admitted to hospital with a presumptive diagnosis of $\mathrm{CO}$ poisoning. Unfortunately this diagnosis could not be substantiated because the patient was given oxygen for several hours before a diagnostic blood sample was taken; however, blood samples taken later from two other workers in the same showroom showed carboxyhaemoglobin saturations $\left(\mathrm{Hb}_{\mathrm{co}} \%\right.$ ) of 22 (nonsmoker) and 28 (smoker, 25 cigarettes a day), respectively. The source of the $\mathrm{CO}$ was the garage's central heating system. This was of the hot air type with an enclosed combustion chamber, with its air intake, not in the open air as common sense would suggest, but in the main garage workroom where car engines were being run without local exhaust ventilation!

Enquiries revealed that it is unusual for local garages to have adequate means of preventing air contamination by exhaust fumes, hence this investigation.

\section{Methods}

SUBJECTS

Garages in Leicester and Leicestershire were visited

Received for publication 29 June 1978

Accepted for publication 12 January 1979 without warning, and venous blood samples were taken from mechanics in each. Individual mechanics were free to refuse to give a blood sample, the acceptance rate being about $80 \%$ of those asked. All visits were made after $4 \mathrm{pm}$ because we wanted to sample the results of the day's $\mathrm{CO}$ build-up.

Two groups of garages were studied. Nine of the large main dealers, each employing more than ten mechanics, were visited in winter when the outside air temperature was below $5^{\circ} \mathrm{C}$. In our experience these are the circumstances which encourage $\mathrm{CO}$ build-up, and we wanted to see what happened under the worst conditions. Twenty-four randomly chosen garages, comprising the second group, were visited throughout the year, two per month. The number of mechanics employed in each ranged from 0 to 16 , but was mostly 0,1 or 2 , a reflection of the fact that, main dealers apart, most Leicestershire garages are small or very small. Twenty-six blood samples were obtained from mechanics in the first group of garages and 35 from those in the second group of garages.

\section{COLLECTION AND ANALYSIS OF SAMPLES}

Blood samples were collected into $5 \mathrm{ml}$ glass bottles containing EDTA as an anticoagulant (Labco Ltd). These were filled with blood and tightly secured. All analyses were completed within $24 \mathrm{~h}$ of collecting the blood.

The $\mathrm{Hb}_{\mathrm{co}} \%$ was determined by the method described by Conway (1957). Briefly, carbon monoxide was liberated from the blood by addition of sulphuric acid in a Conway microdiffusion unit, and absorbed in palladium chloride solution. During incubation of this solution free palladium and hydrochloric acid are formed, and the latter is titrated with potassium hydroxide, thus permitting calculation of 238 
the amount of $\mathrm{CO}$ liberated.

The measured results were corrected in accordance with the calibration curve shown in Figure 1. To produce this curve, $\mathrm{Hb}_{\mathrm{co}}$ standards were made by anaerobically mixing variable quantities of blood which had been equilibrated with $100 \% \mathrm{CO}$ and blood which had been equilibrated with oxygen. Due allowance was made for dissolved carbon monoxide.

\section{Results}

The blood carboxyhaemoglobin saturations $\left(\mathrm{Hb}_{\mathrm{co}} \%\right)$ found in the 26 mechanics in the large garages in winter are shown in Figure 2. Taking the upper limit of blood $\mathrm{Hb}_{\mathrm{co}} \%$ in non-occupationally exposed workers to be 5 in non-smokers and 10 in smokers (see Discussion), then 7 out of 16 nonsmokers $(43.8 \%)$, and 2 out of 10 smokers $(20.0 \%)$ show evidence of excessive $\mathrm{CO}$ absorption. Three $(11.5 \%)$ had blood $\mathrm{Hbco} \%$ above 15 , the highest being 26.0 in a non-smoker.

The $\mathrm{Hb}_{\mathrm{co}} \%$ values in the randomly chosen garages are shown in Figure 3, and the individual results in Figure 4. Six out of 14 non-smokers $(42.9 \%)$, and 3 out of 21 smokers $(14.3 \%)$ show evidence of excessive $\mathrm{CO}$ absorption, and two $(5 \cdot 7 \%)$ had blood $\mathrm{Hb}_{\mathrm{co}} \%$ levels above 15 , the highest being 21.0 in a non-smoker.

Rather surprisingly there is little evidence in Figure 4 that $\mathrm{CO}$ absorption is more of a problem in winter than in summer, when natural ventilation of garage workrooms tends to be increased.

\section{Discussion}

Heliövaara et al. (1978) measured blood carboxyhaemoglobin levels in a randomly chosen group of non-occupationally exposed men, and found that roughly $95 \%$ lay below $3 \%$ in non-smokers and $: 8 \%$ in smokers. On this basis we suggest that an $\mathrm{Hb}$ co $\%$ above 5 in a non-smoker and 10 in a smoker is evidence of occupational exposure to $\mathrm{CO}$. In the present investigation these levels were exceeded by $43.3 \%$ of the non-smokers and $16.1 \%$ of the smokers; blood $\mathrm{Hb}$ co $\%$ values above 15 were found in 5 individuals $(8 \cdot 2 \%$ of total).

In the last decade there have been three studies of blood $\mathrm{Hb}_{\mathrm{co}}$ levels in garage workers in other countries; but none to our knowledge in Britain. Buchwald (1969) looked at this problem in the winter months in Alberta, Canada, and found evidence of $\mathrm{CO}$ overexposure (on the above-defined criteria) in $32 \%$ of workers, with $5 \%$ exceeding a $\mathrm{Hb}$ co $\%$ level of 15 . Köhl and Lob (1975) studied garage workers in 7 garages in Lausanne, Switzerland, and found $\mathrm{Hb}$ co $\%$ average values ranging from 3.7 to 11.3 with a highest individual result of 19 in a moderate smoker. Clausen and Rastogi (1977) found that $19 \%$ of autoworkers in Swedish garages had $\mathrm{Hb}_{\text {co } \%}$ levels in excess of 12, but do not give further details.

Our results, therefore, do not differ greatly from those of other workers, although they suggest that $\mathrm{CO}$ exposure is rather greater in garages in Leicester and Leicestershire than in Alberta or Lausanne. This is not entirely surprising because all the garages in the Swiss study, and the majority of those in the Canadian one were provided with ducting for extraction of exhaust gases, whereas such local extraction was available in only two of the Leicester garages. Further, Köhl and Lob measured atmospheric CO levels in their garages, and the highest value they

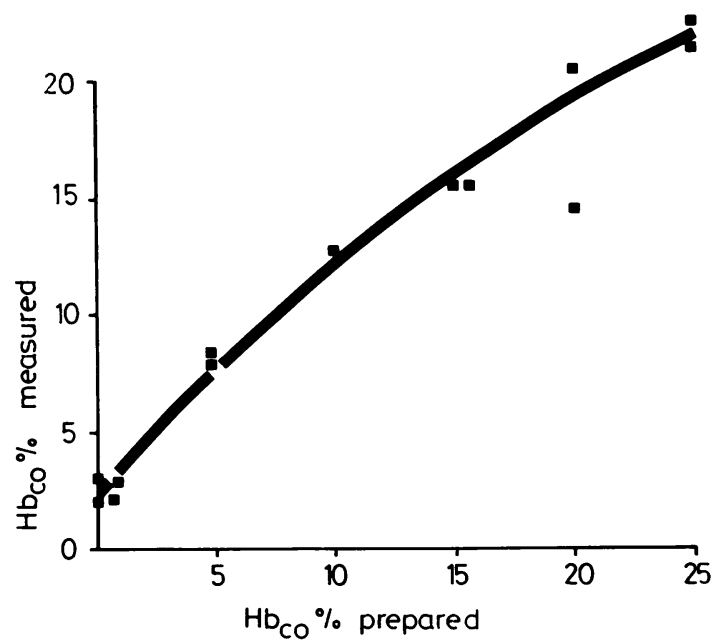

Fig. 1 Calibration curve for $\mathrm{Hb}_{\mathrm{co}}$ measurements (see text).

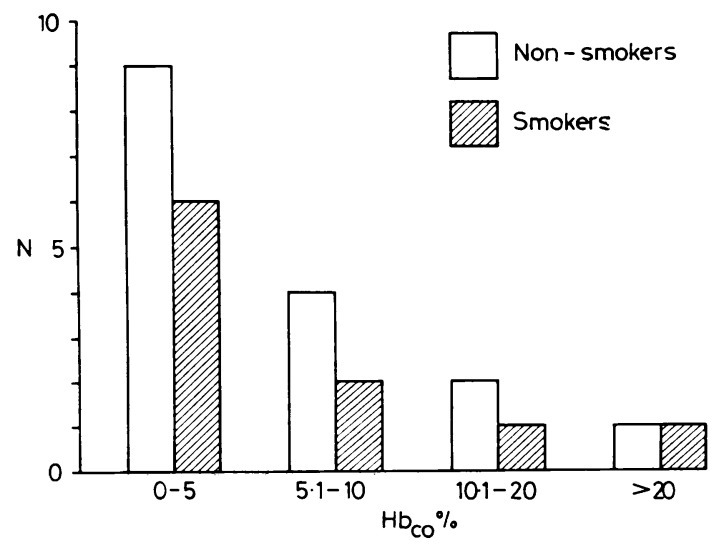

Fig. $2 H b_{\mathrm{co}} \%$ levels in 26 workers in large garages in winter. 


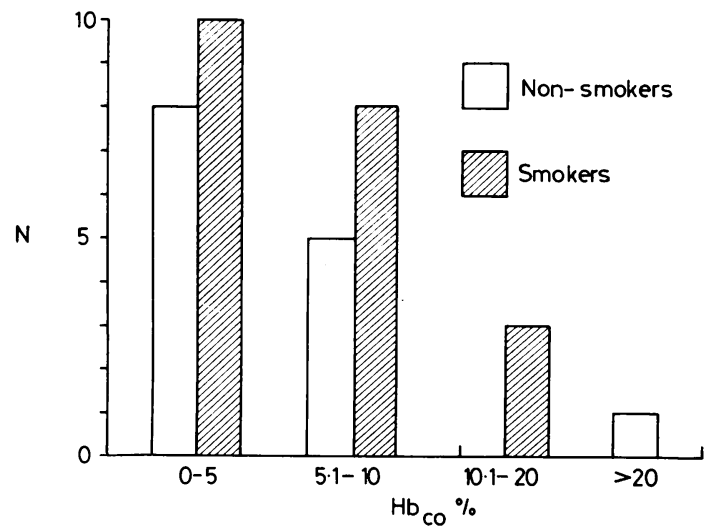

Fig. $3 \mathrm{H} b_{\mathrm{CO}} \%$ levels in 35 workers in random sample of garages (see text).

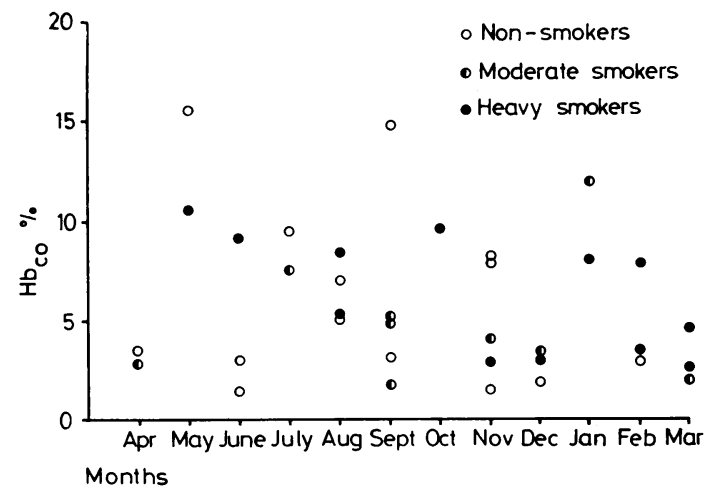

Fig. $4 \mathrm{Hb} b_{\mathrm{co}} \%$ levels in 35 workers in random sample of garages, variation with time of year; heavy smoker $>15$ cigarettes/day; moderate smoker $\leqslant 15$ cigarettes/ day or pipe smoker.

found was $77 \mathrm{ppm}$, with all the others below $50 \mathrm{ppm}$ : we measured atmospheric $\mathrm{CO}$ levels in two of the large garages in our study, and found levels of $\mathbf{1 1 0}$ and $130 \mathrm{ppm}$, respectively. The present TLV for CO is $50 \mathrm{ppm}$.

Thus there is evidence of significant $\mathrm{CO}$ absorption in a substantial proportion of the garage workers included in the present investigation, and it is necessary to consider whether such absorption is likely to be of medical importance.

It has been shown experimentally (Stewart et al., 1970) that exposure of normal subjects to CO sufficient to produce $\mathrm{Hb}_{\mathrm{co}} \%$ levels of 15 caused mild headaches, and that higher levels induced severe frontal headaches which were made worse by exer- cise and persisted even after exposure had ceased. We have no accurate figures but it is noteworthy that many of the workers we studied had symptoms, such as headache, muzziness and impaired concentration, which they attributed to poor ventilation at work. Köhl and Lob (who found rather lower $\mathrm{Hb}_{\mathrm{co}} \%$ levels than those in the present study) found similar symptoms in some $34 \%$ of the workers they investigated.

There is also quite a body of circumstantial evidence which links chronic exposure to low concentrations of $\mathrm{CO}$ with the development of coronary heart disease; although in the absence of more direct epidemiological evidence this must be treated with circumspection, we think it is sufficiently impressive to warrant a brief review here.

Astrup et al. (1967) showed that chronic exposure of cholesterol-fed rabbits to levels of $\mathrm{CO}$ sufficient to give blood $\mathrm{Hb}_{\mathrm{co}} \%$ levels of about 15 caused the appearance of atheroma-like arterial lesions. This finding has since been repeated in primates (Birnstingl et al., 1970; Webster et al., 1970). In addition, Thomsen and Kjeldsen (1974) showed that holding the $\mathrm{Hb}_{\mathrm{co}}$ level of rabbits at $18 \%$ for two days resulted in myocardial ultrastructural changes.

Ayres et al. (1970) showed, in both dogs and humans, that blood $\mathrm{Hb}_{\text {co levels of } 5-10 \% \text { caused an }}$ increase of coronary blood flow with a decrease of coronary arteriovenous oxygen difference. If, therefore, the coronary blood flow was unable to increase because of atheroma, this degree of carboxyhaemoglobinaemia would be expected to cause myocardial hypoxia. It would seem that this is, indeed, the case, because Anderson et al. (1973), in a double-blind and properly controlled trial, showed that even very low $\mathrm{Hb}_{\mathrm{co}} \%$ levels caused a significant decrease of the amount of exercise needed to induce angina, and also an increase in the duration of the pain. Aronow and Isbell (1973) found a similar result, and De Bias et al. (1976) found that blood $\mathrm{Hb}_{\mathrm{co}} \%$ levels of around 10 increased the susceptibility of primate hearts to electrically induced ventricular fibrillation.

Our findings relate to a small number of garages in one part of the country only. However, there seems no reason to doubt that similar results would be obtained more widely. On the basis of these findings, taken in conjunction with the above experimental evidence from the literature, we suggest that $\mathrm{CO}$ may play a part in inducing, or exacerbating, coronary heart disease in garage workers: we suggest that garage proprietors should take more care than they do at present to prevent build-up of $\mathrm{CO}$ in their premises. This can be done fairly readily by installing local exhaust ventilation to remove the $\mathrm{CO}$ at source, and/or by improving the general ventilation of areas where petrol engines must be run indoors. 


\section{References}

Anderson, E. W., Andelman, R. J., Strauch, J. M., Fortuin, N. J., and Knelson, J. H. (1973). Effect of low-level carbon monoxide exposure on onset and duration of angina pectoris. Annals of Internal Medicine, 79, 46-50.

Aronow, W. S., and Isbell, M. W. (1973). Carbon monoxide effect on exercise-induced angina pectoris. Annals of Internal Medicine, 79, 392-395.

Astrup, P., Kjeldsen, K., and Wanstrup, J. (1967). Enhancing influence of carbon monoxide in the development of atherosclerosis in cholesterol-fed rabbits. Journal of Atherosclerosis Research, 7, 343-354.

Ayres, S. M., Giannelli, S., and Mueller, H. (1970). Myocardial and systemic responses to carboxyhaemoglobin. Annals of the New York Academy of Sciences, 174, 268-293.

Birnstingl, M., Hawkins, L., and McEwen, T. (1970). Experimental atherosclerosis during chronic exposure to carbon monoxide. European Journal of Surgical Research, 2, 92-93.

Buchwald, H. (1969). Exposure of garage and service station operatives to carbon monoxide: a survey based on carboxyhaemoglobin levels. American Industrial Hygiene Association Journal, 30, 570-575.

Clausen, J., and Rastogi, S. C. (1977). Heavy metal pollution among autoworkers. British Journal of Industrial Medicine, $34,216-220$.
Conway, E. J. (1957). In Microdiffusion Analysis and Volumetric Error, 4th Edition, p. 326. Crosby Lockwood and Sons: London.

De Bias, D. A., Banerjee, C. M., Birkhead, N. C., Green, C. H., Scott, S. D., and Harrer, W. V. (1976). Effects of carbon monoxide inhalation on ventricular fibrillation. Archives of Environmental Health, 31, 42-46.

Heliövaara, M., Karvonen, M. J., Vilhunen, R., and Punsar, S. (1978). Smoking, carbon monoxide, and atherosclerotic disease. British Medical Journal, 1, 268-270.

Köhl, U., and Lob, M. (1975). Risques d'oxycarbonisme chronique dans les garages. Schweitzerische Medizinische Wochenschrift, 105, 50-56.

Lawther, P. J. (1975). Carbon monoxide. British Medical Bulletin, 31, 256-260.

Stewart, R. D., Peterson, J. E., Baretta, E. D., Bachand, R. T., Hosko, M. J., and Herrmann, A. A. (1970). Experimental human exposure to carbon monoxide. Archives of Environmental Health, 21, 154-164.

Thomsen, H. K., and Kjeldsen, K. (1974). Threshold limit for carbon monoxide-induced myocardial damage: an electron microscopic study in rabbits. Archives of Environmental Health, 29, 73-78.

Webster, W. S., Clarkson, T. B., and Lofland, H. B. (1970). Carbon monoxide-aggravated atherosclerosis in the squirrel monkey. Experimental and Molecular Pathology, 13, 36-50. 